\title{
Thai nurse cohort study: cohort profiles and key findings
}

\author{
Krisada Sawaengdee', Viroj Tangcharoensathien' ${ }^{1}$, Tuangtip Theerawit ${ }^{1}$, Petsunee Thungjaroenkul ${ }^{2}$, \\ Wilaiphorn Thinkhamrop ${ }^{3}$, Panuwat Prathumkam³, Nathaphop Chaichaya ${ }^{3}$, Kavin Thinkhamrop ${ }^{3}$, \\ Chaiwat Tawarungruang ${ }^{3}$ and Bandit Thinkhamrop ${ }^{1,3,4^{*}}$
}

\begin{abstract}
Background: Globally, the nursing profession faces shortages, high turnover, and inequitable distribution. These problems are particularly acute in South East Asia. The present paper describes the design and initial findings of the Thai Nurse Cohort Study (TNCS).

Methods: The TNCS is a longitudinal prospective cohort study comprising multiple age cohorts, initiated in 2009 and expected to run until 2027. Cohorts comprise registered nurses (RN) holding professional licenses granted by the Thailand Nursing and Midwifery Council. Follow-up is at 3-year intervals, with new (younger) TNCS cohorts introduced and older, no-longer eligible members checked out. This maintains the cohort size as representative of the Thai RN population. The first survey round (2009) used a self-administered mailed questionnaire. The second round (2012) provided follow-up of the initial cohort and formed the baseline survey of new entries.

Results: The sampling frame for the first round was 142,699 licensed RN; 50,200 age-stratified participants were randomly selected and mailed the questionnaire, and 18,198 questionnaires were returned owing to incorrect addresses. Of the remaining 32,002 participants, 18,756 (58.6\%) responded (average age $43.7 \pm 9.8$ years). About $15.4 \%$ (equivalent to 20,000 of the current RN population), reported an intention to leave their nursing career. The second round achieved a follow-up rate of $60.2 \%$. This round included 3020 participants randomly selected from 6402 new RN (response rate, $38.3 \%$; mean age $23.1 \pm 3.5$ years). In this round, $11.2 \%$ reported they intended to leave nursing in the next 2 years.

Conclusions: These two survey rounds have highlighted that Thailand is facing critical nurse shortages. A high rate of nurses expressed an intention to leave the profession; the capacity to replace these potential losses is much lower.
\end{abstract}

Keywords: Nurse cohort, Workforce shortage, Inequitable distribution, Women's health

\section{Background}

Globally, the nursing profession is facing shortages, high turnover, and inequitable distribution of the nursing workforce $[1,2]$. These are particularly acute problems for South East Asia (SEA), where the nurse-to-population ratio is approximately $2-3$ nurses per 1000 population [3], ten times lower than that in Europe although higher than in Sub-Saharan African countries [4]. In SEA, the

\footnotetext{
* Correspondence: bandit@kku.ac.th

'Thai Nurse Cohort Study (TNCS), International Health Policy Program, Ministry of Public Health, Tiwanon Rd., Nonthaburi 11000, Thailand

${ }^{3}$ Data Management and Statistical Analysis Center (DAMASAC), Faculty of

Public Health, Khon Kaen University, Khon Kaen 40002, Thailand

Full list of author information is available at the end of the article
}

aging population and high incidence of chronic noncommunicable diseases is increasing the demand for nursing and other social care personnel. Moreover, an aging nurse population, lower rates of replenishment by young nurses, and attrition through international migration to high income countries has considerably increased the pressure on the diminishing nurse workforce $[5,6]$. The Association of South East Asian Nations (ASEAN) Economic Community (AEC) facilitates the free flow of skilled labor across the AEC, and may have major repercussions on nursing demand and supply in the region [7] where capabilities of health system in attracting and retaining their local staff are 
unknown [8]. A review suggested that a study investigating these issues conducted locally is essential [9].

Another alarming sign is that aging of nursing profession has been reported in many countries [10-12]. These comprise a large component of the current nurse population and gradually approaching retirement. In addition, the decline in younger women choosing nursing as a career is also observed. However, information about the retirement rate of nurses is limited.

Although numerous studies have identified factors influencing both the supply and demand of nurse labour, most of these studies were conducted in Western countries $[5,6,13]$. Furthermore, most studies investigating nursing crisis are cross-sectional studies. Cohort studies have greater potential to address the crisis as well as the emerging issues in women's health such as breast cancer, cervical cancer, osteoporotic fractures, postmenopausal illness and its consequence, etc. The study of this kind includes the oldest and the largest nurse cohort study, the Nurse Health Study, initiated in 1976 in the Unites States which focused in cancer and other illnesses [14, 15]. The Danish Nurse Cohort Study (DNCS) established in 1993 investigated working conditions and health including hormone therapy use and risk factors of various health outcomes [16]. The Japan Nurses' Health Study (JNHS), initiated in 2001, investigated effects of lifestyle and healthcare practices on women's health $[17,18]$. The Nurses and midwives e-Cohort Study, established in 2006, aimed to examine factors associated with recruitment and retention of the nursing and midwifery workforce among nurses in Australia and New Zealand [19]. Recently in 2009, the Nurses' Early Exit Study (NEXT), a cross-cultural and longitudinal project conducted in ten European countries to analyze the relationship between working conditions and nursing workers' health $[20,21]$. Then Thailand established a nurse cohort study.

A longitudinal cohort study on the health and working life of registered nurses in Thailand was launched in 2009. The Thai Nurse Cohort Study (TNCS) is a 20-year prospective cohort study designed to generate evidence on the workforce dynamics and health status of Thai nurses. Specifically, the TNCS aims to: 1) determine rates, patterns, trends and determinants of job transition, and 2) assess the prevalence, incidence, and long term changes of key health problems among Thai nurses.

It is expected that the TNCS data will clarify a number of key policy and research questions for Thailand, a middle income country; particularly as numerous other studies have investigated nurse populations in highincome countries $[14,22]$. The cohort design of the TNCS also has potential to address the dynamics of job transition across public and private sectors, migration, determinants of attrition and retention, and to monitor the impact of policy interventions.

\section{Methods}

\section{Study design}

The TNCS uses a longitudinal design, comprising multiple age cohorts of registered nurses (RN) who hold professional licenses granted by the Thailand Nursing and Midwifery Council (TNC). Participants were selected using age-stratified random sampling using 5-year age groups, from 20 to 64 years (nine age groups in total). The first round, representing the baseline survey, was sampled in September 2009. Data were collected using a self-administered mailed questionnaire.

The TNCS was designed to enroll new members every 3 years, with these new entry cohorts named according to the year of inclusion. New entry cohorts will be sampled from RN newly registered with the TNC and listed in the TNC database. This means the TNCS will have multiple cohorts: the initial cohort collected in 2009, a 2012 new entry cohort, and proposed subsequent new entry cohorts (the 2015, 2018, 2021, 2024, and 2027 cohorts). Cohort members will be followed until 2030, unless they withdraw from participation, are diagnosed with cancer, reach the age of 68 years, or pass away. The second round of the survey, conducted in 2012, served as a follow-up for the initial cohort and provided baseline data for the new entry cohort. The second survey was administered using a mixed mode, either a mailed questionnaire or web-based survey, depending on that member's preferences. For future surveys, a web-based questionnaire is planned because of the high cost implications of mailed questionnaires.

\section{Measurements}

The questionnaire in the first survey comprised three main sections (Table 1): personal data (birth date, address, marital status, education, income, debt, and other burdens); employment characteristics, job transition since graduation, and job strain questions modified from the Job Content Questionnaire short version (JCQ) [23]; and health status, including the EuroQol five-dimension questionnaire (EQ-5D) [24], the short form of the International Physical Activity Questionnaire (IPAQ) [25], history and current illness, and self-care activities. The follow-up survey repeated the employment and health status sections.

\section{Sample size calculation}

A sample size of 30,000 was initially planned, based on the aim of detecting any events with a proportion as low as $1 \%$ with $+/-0.1 \%$ precision (i.e., it offered a relative precision of $+/-10 \%$ with a two-sided $95 \%$ confidence level). We also allowed $40 \%$ for expected non-responses because of invalid contact addresses, refusal to participate, and loss to follow-up; this excess was slightly better than that used in a study involving nurses in Japan [26]. 
Table 1 Parameters and their use in the baseline survey of the Thai Nurse Cohort Study

Parameters
A. Demographic and socio-economics characteristics
o Thai citizen identification number to be used for ascertainment of
morbidity and mortality status in National Health and Death Registry
Databases (password protected access)

o Birth place (province and district)

o Birth date or age, sex, marital status

o Month and year of nursing graduation

o Month and year of started working and employment status

o Institute from which being graduated (public college under the Ministry of Public Health, public university, private educational institute)

o Education (highest level of educational, specialized training, scholarship)

o Economic status (income, debt, perception of income sufficiency, dependency)

B. Work-life characteristics

B1. Job transition since graduation

o Date start working for each roles or employment

o Type of work: service and non-service (administrative, teaching)

o Leaving nursing for other careers or for un-employ

o Study leave

o Place of work (public versus private, inside versus outside birthplace)

B2. Employment characteristics and working intensity

o Current employment status (government, private, freelance, others)

o Current position (nursing services, administration, research, academic, others)

o Current workplace category (hospital, health care center or unit, under study leave, others)

o Full time part-time employment,

o Work shift arrangement,

o Work under night shift,

o Working hours per week

o Other job in addition to nursing
Use

o Estimating rate of morbidity and mortality for overall and specific to causes or other subgroups

o Simultaneously monitoring long-term changes of morbidity and mortality and their determinants

o Investigating survival outcome (time to disease, disease progression, dead) o Estimating life expectancy of nurses and its 20 year trends

o Determining long-term effect of various factors on mortality and morbidity

o Reflecting women health status in Thailand

o Characterizing geographically distribution of nurses

o Describing work place preference against birth place

o Explaining and predicting Job turnover and retention

o Testing hypotheses about scholarship or other incentives for working in underserved area

o Investigating their effects on job turnover and health statuses

o Estimating median survival of working in nursing profession

o Estimating duration of work

o Estimating time gap before employment

o Being a baseline employment for investigation of job turnover

o Investigating its effect on job turnover and health status

o Investigating its effect on retention and workplace preference (urban versus rural, and total survival in profession)

o Being a mode for maximizing follow-up rate such as establishing social network among cohort members

o Determining opportunity of career advancement

- Describing distribution of skilled and skill-mix nursing, comparing between urban and rural

o Investigating effect of scholarship on work retention and nursing distribution

o Investigating its effect on job turnover

o Investigating its effect on stress or various health problems as well as health conditions causing the problems

o Characterizing of job transition pattern over working lifetime

o Monitoring of long-term nursing turnover

o Describing distribution of nurses between major sectors

o Determine pattern of job turnover on intention to stay or leave nursing career

o Estimating duration between certain point in time or type of employment and the turnover

o Estimating of work-life expectancy (It was 22 years according to the latest estimate in 2007.)

o Determine current and long-term trend distribution of nurses according to various type of employments, sectors, and employment status o Describing working load as determinants of job turnover and health o Investigating roles of night-evening shift on job turnover and health o Describing work-life balance profile and its role on job turnover and health 
Table 1 Parameters and their use in the baseline survey of the Thai Nurse Cohort Study (Continued)

B3. Perceived work stresses (21 items, score 1-4 each)

B4. Workplace violence and occupational injuries

o Physical harassment, psychological harassment, from colleagues, patient and their relatives

o Occupation injuries: specify: cut wound, needle stick, chemical and radiation injuries,

o Hospital acquired infections e.g. TB, Hepatitis, HIV/AIDS,

B5. Intension to leave and to return to nursing career

o Intention to leave nursing profession and the reasons for those currently working in nursing profession

o Intention and enabling conditions to return to nursing profession for those currently not engaged in nursing profession

C. Health status and related information

C1. Anthropometrics, daily activities, and sleeping

o Current anthropometric measurements: body weight, height, waist and hip circumference

o Intensity of daily physical activities (duration of heavy, moderate, walk, sit activities)

o Physical activities at leisure

o Average duration of sleeping per day and frequency of sleeping difficulties

C2. History and current illness, and self-care activities

o Family members who had history of illness being diagnosed by medical doctor

o The respondent's history of illness being diagnosed by medical doctor and whether or not currently under treatment

o Annual physical checkup being done and their results with regard to breast self examination, cervical cancer screening, chest film, blood examination, lipid measurements, etc.)

o Health care services being utilized by the respondent during the last 12 months

o Hospitalization during the last 12 months

o Medication used during the last 30 days

o Self assessment of health in the last 30 days based on EuroQol five-dimension questionnaire (EQ-5D)

o Reproductive health for female respondents (pregnancies, delivery, and family planning methods)
- Estimating proportion of nurses with work stress

o Investigating its effect on job turnover

o Investigating its effect on various health problems as well as health

conditions causing the problems

o Estimating proportion of nurses facing workplace violence o Investigating its effect on job turnover

o Estimating rate and trend of occupational injuries

o Investigating its effect on job turnover

o Estimating probability to leave and predicted duration before quit o Investigating its effect on job turnover

o Estimating probability of return to nursing professions, list of potential policy intervention on retention o Investigating its effect on job turnover

o Investigating its effect on job turnover

o Investigating its effect on stress or various health problems as well as health conditions causing the problems

o Estimating prevalence of regular physical activities, compared to general population

o Investigating roles of physical, diets and cholesterol on various chronic diseases and metabolic syndromes

o Investigating its effect on job turnover

o Investigating its effect on stress or various health problems as well as health conditions causing the problems

o Investigating its effect on job turnover

o Investigating its effect on stress or various health problems as well as health conditions causing the problems

o Estimating incidence / prevalence and type of chronic illnesses

o Describing health awareness

o Estimating proportion of nurses who had certain problems regarding various laboratory findings, health measurements, or diseases

o Investigating health profiles

o Investigating health profiles

o Investigating health profiles

o Estimating level of health status according to self-perceptions

o Estimating total fertility rate among nurse, infertility, prevalence and profile
Therefore, the sample size was inflated to 50,000. However, administrative reasons meant that the actual number of questionnaires mailed out was 50,200.

\section{Sampling techniques}

TNCS participants were classified into two categories: the initial cohort and the new entry cohort.

The initial cohort comprised RN who were randomly selected from the TNC database, who signed a consent form, and who responded to the first-wave questionnaire. The TNC database used as the sampling frame included all RN who held nursing licenses granted by the TNC as of 2008, with a total of 142,699 RN forming the sampling frame. We then applied an age-stratified random sampling technique for sample selection. First, RN aged 20-64 years were stratified into nine age groups based on 5-year intervals $(<25,25-29,30-34$, $35-39,40-44,45-49,50-54,55-59$, and 60-64 years). 
Based on the sample size of 50,000, the average size of each age group was calculated as 5556 nurses. However, as the oldest two age groups (55-59, and 60-64 years) were smaller than the average size, we selected all members of these groups. Participants from the remaining seven age groups were randomly selected. First, a set of random numbers were generated using Stata statistical software (StataCorp, College Station, TX). This assigned a random number to each nurse's Citizen Identification Number (CID). CID were then sorted according to the assigned random numbers. Nurses in each age group were listed in the sorted order. Finally, nurses were selected consecutively, starting from the first order, until the specified size was achieved. The sample size was equal for all seven age groups. For administrative reasons, a total of 50,200 nurses were eventually selected for the initial cohort.

The new entry cohort included all RN who held nursing licenses granted by the TNC after 2008 and were not part of the sampling frame of the initial cohort. From a total of $6402 \mathrm{RN}$ in this group, 1600 (25\%) were randomly selected. The selection methods as used for the initial cohort were applied.

\section{Statistical methods}

We provided the probability of responses as the inverse proportion to the probability of responses to be used in subsequent papers for weighting in statistical analyses. To describe the cohort profile, we presented the results as number and percentage for categorical variables, and mean and standard deviation (SD) for continuous variables. These descriptive statistics were used for demographic characteristics, employment history and career advancement, current employment status, intention to leave the nursing profession within the next 2 years, and quality of life based on the EuroQol five-dimensions, in both the initial and the new entry cohorts. All analyses were performed using STATA version 13 (StataCorp).

\section{Ethics and good clinical practice}

The present study was conducted according to the principles of Good Clinical Practice (International Conference on Harmonization Tripartite Guideline for Good Clinical Practice), the Declaration of Helsinki, and national laws and regulations for clinical studies. The TNCS was approved by the Thai Ministry of Public Health Ethics Committee for

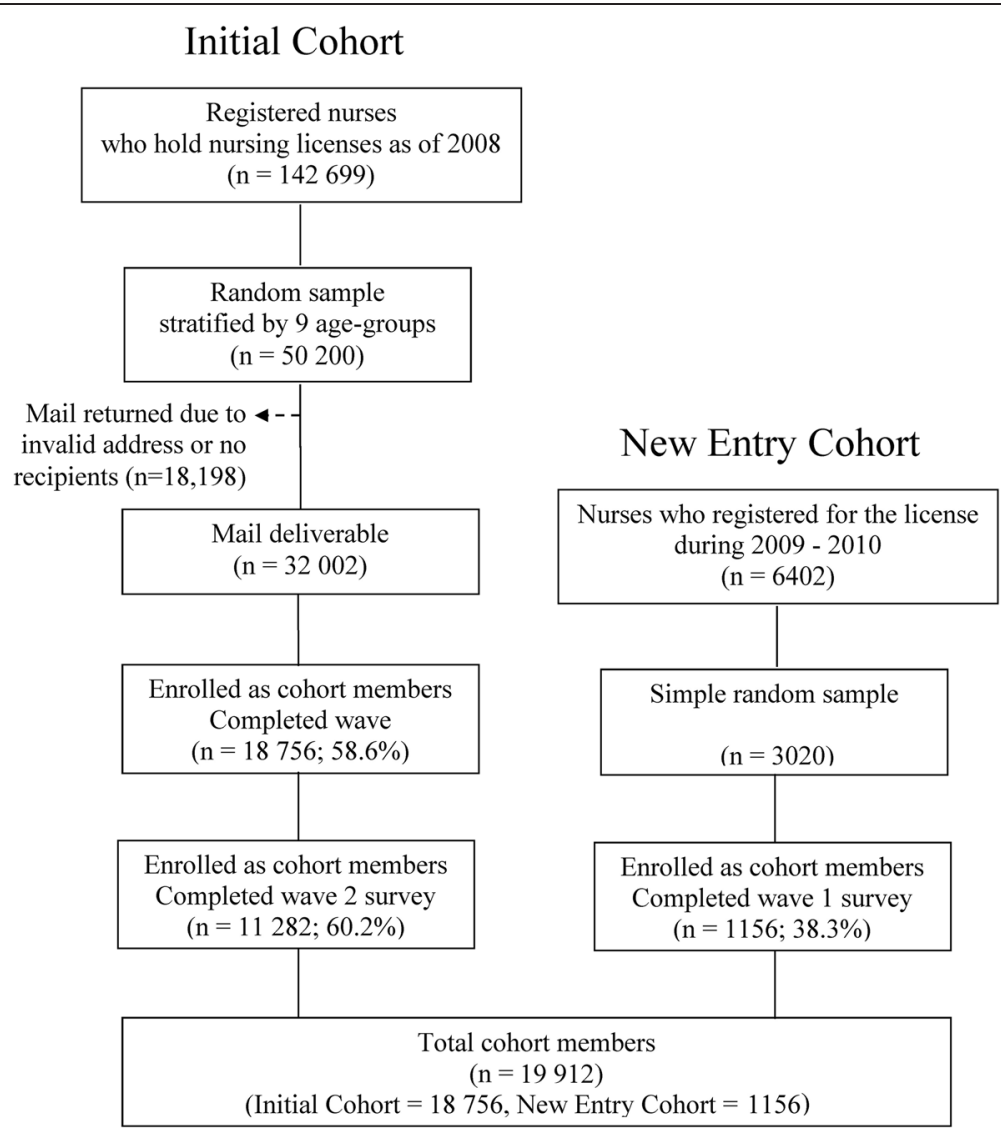

Fig. 1 Population, sample, and respondents of the baseline survey of the Thai Nurse Cohort Study 
Table 2 Recommended weight for data analysis of the initial cohort of the Thai Nurse Cohort Study

\begin{tabular}{lllll}
\hline Age group & Population & Respondents & Probability & Weight \\
\hline Lower than 25 & 9352 & 747 & 0.0799 & 12.5194 \\
$25-29$ & 22664 & 1308 & 0.0577 & 17.3272 \\
$30-34$ & 32807 & 1760 & 0.0536 & 18.6403 \\
$35-39$ & 24400 & 2690 & 0.1102 & 9.0706 \\
$40-44$ & 21760 & 3155 & 0.1450 & 6.8970 \\
$45-49$ & 17640 & 3584 & 0.2032 & 4.9219 \\
$50-54$ & 7827 & 2971 & 0.3796 & 2.6345 \\
$55-59$ & 4572 & 2043 & 0.4469 & 2.2379 \\
60 or greater & 1677 & 498 & 0.2970 & 3.3675 \\
Total & 142699 & 18756 & & \\
\hline
\end{tabular}

Human Research. All participants signed a consent form for participation as a cohort member of the TNCS.

\section{Results \\ Questionnaire responses and recommended weighting for statistical analysis}

In total, 50,200 questionnaires were sent via postal mail for the first survey wave, 18,198 (36.3\%) were returned owing to invalid addresses or no recipient (Fig. 1). There were 18,756 questionnaires returned with signed and dated consent forms. This gave a response rate of $58.6 \%$ for the 32,002 deliverable questionnaires, assuming the questionnaires were received. The first 10,000 responses were received within 2 months of the mail out.

Although the overall response rate for the first survey was $58.6 \%$ (Fig. 1), the three younger age groups had the lowest response rates (see Table 2 for the probability

Table 3 Demographic characteristics of first-wave survey respondents, presented as number and percentage unless indicated otherwise

\begin{tabular}{|c|c|c|c|c|}
\hline \multirow[t]{2}{*}{ Characteristics } & \multicolumn{2}{|c|}{$\begin{array}{l}\text { Initial Cohort } \\
(n=18756)\end{array}$} & \multicolumn{2}{|c|}{$\begin{array}{l}\text { New Entry Cohort } \\
(n=1156)\end{array}$} \\
\hline & $n$ & $(\%)$ & $n$ & (\%) \\
\hline \multicolumn{5}{|l|}{ Sex } \\
\hline Male & 625 & (3.3) & 75 & $(6.8)$ \\
\hline Female & 18013 & $(96.7)$ & 1029 & $(93.2)$ \\
\hline \multicolumn{5}{|l|}{ Age (years) } \\
\hline Lower than 25 & 747 & $(4.0)$ & 1119 & $(96.8)$ \\
\hline $25-44$ & 8913 & $(47.5)$ & 24 & $(2.1)$ \\
\hline 45 or greater & 9096 & $(48.5)$ & 13 & $(1.1)$ \\
\hline Mean (Standard deviation) & & $43.2(9.8)$ & & $23.1(3.5)$ \\
\hline \multicolumn{5}{|l|}{ Marital status } \\
\hline Single & 5764 & $(30.9)$ & 950 & $(82.3)$ \\
\hline Married & 11354 & $(60.8)$ & 192 & $(16.6)$ \\
\hline Widowed & 533 & $(2.9)$ & 6 & $(0.5)$ \\
\hline Divorced & 880 & $(4.7)$ & 3 & $(0.3)$ \\
\hline Separated & 152 & $(0.7)$ & 3 & $(0.3)$ \\
\hline \multicolumn{5}{|l|}{ Region of workplace } \\
\hline North & 2234 & $(12.7)$ & 71 & $(16.6)$ \\
\hline Northeast & 4060 & $(23.0)$ & 96 & $(22.5)$ \\
\hline Central & 6828 & $(38.7)$ & 140 & $(32.8)$ \\
\hline East & 1318 & $(7.5)$ & 28 & $(6.6)$ \\
\hline West & 953 & $(5.3)$ & 24 & $(5.6)$ \\
\hline South & 2258 & $(12.8)$ & 68 & $(15.9)$ \\
\hline \multicolumn{5}{|l|}{ Current and highest educational attainment } \\
\hline Certificate equivalent to bachelor's degree & 4289 & $(23.4)$ & 24 & $(2.1)$ \\
\hline Bachelor's degree & 10474 & $(57.2)$ & 1123 & $(97.2)$ \\
\hline Master's degree & 3170 & $(17.3)$ & 8 & $(0.7)$ \\
\hline Doctoral degree & 154 & $(0.8)$ & 0 & (0) \\
\hline Other & 210 & $(1.3)$ & 0 & $(0)$ \\
\hline
\end{tabular}


of responses). For the new entry cohort, the weight was determined based on the inverse proportion of responses, which was 2.61 (3020/1156).

The second round, conducted in August 2012, served as a follow-up for the initial cohort and the baseline survey of the new entry cohort. The follow-up rate for the initial cohort was $60.2 \%$ (11,282 of $18,756 \mathrm{RN}$ who responded in the first round). In the second round, $\mathrm{RN}$ who were registered with the TNC in 2009 and 2010, and who were aged between 23-27 and 22-26 years, respectively, formed the sampling frame of the new cohort. Nurses in the new entry cohort were aged 20-24 years when the sampling frame for first round of the study was established. Of the 7050 newly registered RN, 648 were excluded as their age exceeded the required age range. Of the remaining 6402 new RN, $25 \%$ were identified as the final sample size. To allow for $47 \%$ of nonresponses based on the previous round survey, a sample size of 3020 was required. Of these, 1156 responded and were enrolled as new entry cohort members. The response rate for the new entry cohort was $38.3 \%$ (Fig. 1).

\section{Demographic characteristics}

The majority of the initial cohort members were female $(96.7 \%)$, married $(60.8 \%)$, lived in the central region of the country $(38.7 \%)$, and had attained a bachelor's degree (57.2 \%) (Table 3). About half (48.5\%) were aged older than 44 years. The average age was $43.7 \pm 9.7$ years. The average age of the new entry cohort was $23.1 \pm 3.5$ years, and a much higher proportion were single $(82.3 \%)$.

\section{Employment history and career advancement}

A majority of the initial cohort (78.0 \%) graduated from nursing colleges owned by the Thai Ministry of Public Health; $79.5 \%$ had been serving mandatory nursing service in public sector after graduation; and $63.1 \%$ were employed as RN when they started working, while the remaining nurses started their career as a Technical Nurse (diploma level) (Table 4). Only $7.9 \%$ had graduated from a public university. The new entry cohort showed similar pattern in their employment history. Around 5833 (31.1\%) of the initial cohort had a diploma-level education at first employment, $75.6 \%$ of

Table 4 Employment history and career advancement of the first-wave of the Thai Nurse Cohort Study

\begin{tabular}{|c|c|c|c|c|}
\hline \multirow[t]{2}{*}{ Characteristics } & \multicolumn{2}{|c|}{ Initial Cohort $(n=18$ 756) } & \multicolumn{2}{|c|}{ New Entry Cohort $(n=1156)$} \\
\hline & $n$ & (\%) & $n$ & $(\%)$ \\
\hline \multicolumn{5}{|l|}{ Institute from which graduated } \\
\hline Public university & 1215 & $(7.9)$ & 0 & (0) \\
\hline Nursing colleges under Ministry of Public Health & 11964 & $(78.0)$ & 651 & $(77.8)$ \\
\hline Other nursing colleges & 1590 & $(10.3)$ & 142 & $(17.0)$ \\
\hline Private institutes & 574 & (3.8) & 44 & $(5.2)$ \\
\hline \multicolumn{5}{|l|}{ Having been under contracted scholarship } \\
\hline Yes & 14408 & $(79.5)$ & 712 & $(65.9)$ \\
\hline No & 3712 & $(20.5)$ & 368 & $(34.1)$ \\
\hline \multicolumn{5}{|l|}{ Employment upon started working } \\
\hline \multicolumn{5}{|l|}{ Undergraduate level } \\
\hline Public health worker & 623 & (3.4) & 4 & $(0.3)$ \\
\hline Assistant nurse & 1152 & $(6.2)$ & 0 & (0) \\
\hline Technical nurse & 4220 & $(22.7)$ & 4 & $(0.3)$ \\
\hline \multicolumn{5}{|l|}{ Graduate level } \\
\hline Registered nurse & 11739 & $(63.1)$ & 1103 & $(96.5)$ \\
\hline Nurse lecturer & 190 & $(1.0)$ & 22 & (1.9) \\
\hline Others & 687 & (3.6) & 10 & $(1.0)$ \\
\hline \multicolumn{5}{|l|}{$\begin{array}{l}\text { Career advancement among initial cohorts } \\
\text { who started working at undergraduate level }(n=5833)\end{array}$} \\
\hline Remain unchanged & 1365 & $(23.4)$ & & \\
\hline Upgraded to Bachelor degree & 3915 & $(67.1)$ & & \\
\hline Upgraded to Master degree & 497 & $(8.5)$ & & \\
\hline Upgraded to Doctoral level & 2 & $(0.03)$ & & \\
\hline Others & 54 & $(0.9)$ & & \\
\hline
\end{tabular}


these were trained and upgraded $(67.1 \%$ to a bachelor's degree, $8.5 \%$ to a master's degree, and $0.03 \%$ a doctoral degree). The entire new entry cohort held a bachelor's degree at their first employment.

\section{Current employment status}

A majority of the initial cohort were engaged in nursing services (61.2\%), and $21.0 \%$ were mid-level nursing administrators (Table 5). Around $80.8 \%$ were civil servants and $79.0 \%$ worked in hospitals. Only $9.0 \%$ worked in health centers or private clinics. Again, a similar pattern of current employment was found in the new entry cohort.

\section{Intention to leave nursing career}

Of the 16,470 nurses in the initial cohort who were working in the nursing profession at the time of the baseline survey, 2306 (15.4\%) stated that they intended to leave their nursing career. This proportion was slightly lower in the new entry cohort, with $11.2 \%$ indicating an intention to leave the profession in the next two years (Table 6). The number of nurses intending to leave the profession increased slightly with age. More research nurses reported an intention to leave, $(16.7 \%)$ compared with other employment categories. In the initial cohort, $18.0 \%$ of nurses who worked in research areas and $20.4 \%$ who worked in the private sector reported an intention to leave the profession.

\section{Quality of life, health status}

Overall, the quality of life of Thai RN, based on EQ-5D scores, was good, with an overall mean score of $0.758 \pm$ 0.191 for the initial cohort and $0.751 \pm 0.178$ for the new entry cohort (Table 7). In the initial cohort, the mean quality-of-life score remained unchanged at follow-up ( 3 years after the baseline survey) ( mean $=0.764 \pm 0.193$ ). Across the EQ-5D dimensions, more than half of the Thai RN reported some degree of pain or discomfort, and about one third reported anxiety or depression.

\section{Discussion}

The TNCS was established to help address the Thai nursing workforce crisis, but may also contribute to the understanding of the health of Thai women engaged in

Table 5 Current employment status of the first-wave of the Thai Nurse Cohort Study

\begin{tabular}{|c|c|c|c|c|}
\hline \multirow[t]{2}{*}{ Current employment characteristics } & \multicolumn{2}{|c|}{ Initial Cohort $(n=18756)$} & \multicolumn{2}{|c|}{ New Entry Cohort $(n=1156)$} \\
\hline & $n$ & (\%) & $\bar{n}$ & (\%) \\
\hline \multicolumn{5}{|l|}{ Employment category } \\
\hline Direct care nurse & 11320 & $(61.2)$ & 1094 & $(95.4)$ \\
\hline Nurse lecturer & 554 & (3.0) & 28 & $(2.4)$ \\
\hline $\begin{array}{l}\text { Middle level administrator } \\
\text { (Head ward, Unit manager, Chair of the department) }\end{array}$ & 3886 & $(21.0)$ & 2 & $(0.2)$ \\
\hline $\begin{array}{l}\text { High level administrator } \\
\text { (Director, Dean of the faculty or equivalent) }\end{array}$ & 548 & $(2.9)$ & 0 & (0) \\
\hline Research nurse & 489 & (2.6) & 3 & $(0.3)$ \\
\hline Unemployed & 311 & $(1.7)$ & 16 & (1.4) \\
\hline Others & 1398 & (7.6) & 4 & $(0.3)$ \\
\hline \multicolumn{5}{|l|}{ Main career } \\
\hline Civil servant & 15032 & $(80.8)$ & 228 & $(19.9)$ \\
\hline Government officer & 702 & (3.8) & 558 & (48.6) \\
\hline State enterprise staff & 93 & $(0.5)$ & 17 & $(1.5)$ \\
\hline Private sector staff & 1415 & (7.6) & 329 & $(28.7)$ \\
\hline Freelance & 177 & $(1.0)$ & 1 & $(0.1)$ \\
\hline Others & 1183 & $(6.3)$ & 14 & $(1.2)$ \\
\hline \multicolumn{5}{|l|}{ Workplace } \\
\hline Hospital & 14088 & $(79.0)$ & 1013 & (91.8) \\
\hline Health center, clinic & 1600 & (9.0) & 45 & $(4.1)$ \\
\hline Infirmary in school or other organization & 98 & $(0.6)$ & 1 & $(0.1)$ \\
\hline Nursing school & 592 & (3.3) & 25 & $(2.3)$ \\
\hline Non-health care service office & 498 & $(2.8)$ & 1 & $(0.1)$ \\
\hline Others & 959 & $(5.3)$ & 18 & (1.6) \\
\hline
\end{tabular}


Table 6 Intention to leave the nursing profession within the next 2 years, as reported in the Thai Nurse Cohort Study

\begin{tabular}{|c|c|c|c|c|c|c|}
\hline \multirow{3}{*}{$\begin{array}{l}\text { Subgroups of registered } \\
\text { nurse }\end{array}$} & \multicolumn{4}{|c|}{ Initial Cohort } & \multirow{2}{*}{\multicolumn{2}{|c|}{ New Entry Cohort $(n=1156)$}} \\
\hline & \multicolumn{2}{|c|}{ Wave $1(n=18756)$} & \multicolumn{2}{|c|}{ Wave $2(n=11282)$} & & \\
\hline & Number & $\%$ Intent to leave & Number & $\%$ Intent to leave & Number & $\%$ Intent to leave \\
\hline Overall & 18109 & $(15.4)$ & 10762 & (5.5) & 1127 & $(11.2)$ \\
\hline \multicolumn{7}{|l|}{ Age group } \\
\hline Lower than 25 & 743 & $(10.6)$ & 680 & (5.4) & 1091 & $(11.2)$ \\
\hline $25-29$ & 1289 & $(13.8)$ & 808 & $(6.2)$ & 8 & (0) \\
\hline $30-34$ & 1735 & $(13.7)$ & 942 & (6.3) & 5 & (0) \\
\hline $35-39$ & 2652 & $(15.5)$ & 1340 & $(5.2)$ & 7 & $(14.3)$ \\
\hline $40-44$ & 3108 & $(15.9)$ & 2590 & $(5.5)$ & 3 & (33.3) \\
\hline $45-49$ & 3503 & $(16.0)$ & 1669 & $(4.9)$ & 6 & $(16.7)$ \\
\hline $50-54$ & 2849 & $(16.0)$ & 1439 & (6.3) & 5 & (0) \\
\hline $55-59$ & 1915 & $(15.8)$ & 991 & $(5.2)$ & 2 & $(50.0)$ \\
\hline 60 or greater & 315 & $(18.4)$ & 303 & $(4.0)$ & 0 & (0) \\
\hline \multicolumn{7}{|l|}{ Employment category } \\
\hline Direct care nurse & 11134 & $(15.2)$ & 6756 & (6.0) & 1081 & (11.6) \\
\hline Nurse lecturer & 551 & $(12.7)$ & 289 & (5.9) & 26 & (3.9) \\
\hline Middle level administrator & 3767 & $(15.2)$ & 2760 & $(4.9)$ & 2 & (0) \\
\hline High level administrator & 534 & $(15.0)$ & 416 & (3.4) & 0 & (0) \\
\hline Research nurse & 484 & $(18.0)$ & 254 & (2.8) & 3 & (0) \\
\hline \multicolumn{7}{|l|}{ Main career } \\
\hline Civil servant & 14715 & $(15.2)$ & 9158 & (5.5) & 223 & $(11.7)$ \\
\hline Government officer & 692 & $(11.3)$ & 566 & $(4.8)$ & 551 & (11.4) \\
\hline State enterprise staff & 92 & $(16.3)$ & 117 & (6.8) & 16 & $(12.5)$ \\
\hline Private sector staff & 1392 & $(20.4)$ & 707 & $(6.7)$ & 326 & $(10.7)$ \\
\hline Freelance & 150 & $(12.0)$ & 91 & (3.3) & 1 & (0) \\
\hline Others & 956 & (12.8) & 84 & (1.2) & 4 & (0) \\
\hline
\end{tabular}

a specific profession. To the best of our knowledge, this is the first cohort study with nurses in SEA. Our findings contribute evidence from a middle-income country, where the socioeconomic profile, environment, and health behaviors differ from those of high-income countries. Understanding long-term nursing workforce dynamics and changes in women's health is essential for relevant policy formulation. The TNCS was also established at a time (2009) of significant change, with the integration of 10 ASEAN countries into a single economic community, the AEC. This means that the TNCS can monitor the corresponding changes in the Thai nursing workforce, including the impact of the free flow of the nurse workforce in the AEC on nursing mobility and shortages, and contribute to the introduction of timely workforce policy. The present paper was prepared during the preparations for the third TNCS survey round (2015), which will yield further information on the impact of the AEC.
In addition, the nine age-groups covered by the initial TNCS cohort will contribute to the understanding of job transition dynamics; while the regular replenishment of the cohort with younger age groups will contribute to a timely understanding of the work and life dynamics of the younger professional group, allowing new questions to be addressed. This design has many advantages over conventional single-age cohort studies, as highlighted in previous research [27].

The baseline survey response rate for the initial cohort $(58.6 \%)$ was similar to or greater than some other large studies conducted among the nursing profession $[14,18,22]$. However, we remain concerned about the lower response rate $(38.3 \%)$ for the new entry cohort, and more effort may be necessary to ensure a more favorable response rate in future.

A steering committee including key partners and stakeholders provided advisory support to the TNCS secretariat. These include 1) President of the Thailand 
Table 7 Quality of life based on the EuroQol five-dimensions in the Thai Nurse Cohort Study, presented as number and percentage unless indicated otherwise

\begin{tabular}{|c|c|c|c|c|c|c|}
\hline \multirow[t]{3}{*}{ Subgroups of registered nurse } & \multicolumn{4}{|c|}{ Initial Cohort } & \multirow{2}{*}{\multicolumn{2}{|c|}{$\begin{array}{l}\text { New Entry Cohort } \\
(n=1156)\end{array}$}} \\
\hline & \multicolumn{2}{|c|}{ Wave $1(n=18756)$} & \multicolumn{2}{|c|}{ Wave $2(n=11282)$} & & \\
\hline & $n$ & $(\%)$ & $n$ & (\%) & $n$ & $(\%)$ \\
\hline \multicolumn{7}{|l|}{ Mobility } \\
\hline I have no problems in walking about & 14180 & $(76.0)$ & 8392 & $(74.9)$ & 944 & $(82.4)$ \\
\hline I have some problems in walking about & 4445 & $(23.9)$ & 2807 & $(25.0)$ & 199 & $(17.4)$ \\
\hline I am confined to bed & 25 & (0. 1) & 9 & $(0.1)$ & 2 & $(0.2)$ \\
\hline \multicolumn{7}{|l|}{ Self-Care } \\
\hline I have no problems with self-care & 18266 & $(97.9)$ & 10923 & $(97.4)$ & 1120 & $(98.1)$ \\
\hline I have some problems washing or dressing myself & 385 & $(2.1)$ & 279 & $(2.5)$ & 22 & $(1.9)$ \\
\hline I am unable to wash or dress myself & 7 & $(0.0)$ & 8 & $(0.1)$ & 0 & (0) \\
\hline \multicolumn{7}{|l|}{ Usual Activities } \\
\hline I have no problems with performing my usual activities & 15439 & $(82.8)$ & 9470 & $(84.5)$ & 922 & $(80.6)$ \\
\hline I have some problems with performing my usual activities & 3130 & $(16.8)$ & 1696 & $(15.1)$ & 220 & $(19.2)$ \\
\hline I am unable to perform my usual activities & 88 & $(0.4)$ & 39 & $(0.4)$ & 2 & $(0.2)$ \\
\hline \multicolumn{7}{|l|}{ Pain/Discomfort } \\
\hline I have no pain or discomfort & 8347 & $(44.8)$ & 5075 & $(45.3)$ & 445 & (38.9) \\
\hline I have moderate pain or discomfort & 9910 & $(53.2)$ & 5858 & $(52.3)$ & 676 & $(59.2)$ \\
\hline I have extreme pain or discomfort & 389 & $(2.0)$ & 265 & $(2.4)$ & 22 & (1.9) \\
\hline \multicolumn{7}{|l|}{ Anxiety/Depression } \\
\hline I am not anxious or depressed & 11210 & $(60.2)$ & 7475 & $(66.8)$ & 683 & (59.8) \\
\hline I am moderately anxious or depressed & 7135 & $(38.3)$ & 3599 & $(32.1)$ & 436 & $(38.1)$ \\
\hline I am extremely anxious or depressed & 283 & $(1.5)$ & 124 & $(1.1)$ & 24 & (2.1) \\
\hline Mean (standard deviation) overall score & 0.758 & $(0.191)$ & 0.764 & (0.193) & 0.751 & $(0.178)$ \\
\hline
\end{tabular}

Nursing and Midwifery Council (Chair), 2) Director, the International Health Policy Program (Vice Chair), 3) President, Thai Nurse Association, 4) President, Consortium of Dean of Nursing Schools, 5) Director, Bureau of Policy and Strategy, Ministry of Public Health, 6) Director, Nursing Systems Research Institute, Thailand Nursing and Midwifery Council, 7) Director, Prabomarajchanok Institute for Health Workforce Development, Ministry of Public Health, 8) Director, Health Systems Research Institute, 9) Director, HRH Research and Development Office, 10) Director, Bureau of Nursing, Ministry of Public Health, 11) Representative from the National Health Security Office, and 12) Representative from the National Health Commission. The Steering Committee is responsible for oversight and support of the work of TNCS, in line with the specified goals and objectives.

Maintaining a professional cohort with a high rate of follow-up responses and low costs was challenging. We designed the TNCS as part of the existing routine data collection system. First, updated postal addresses and other essential follow-up data including job transition and health status were fully embedded in a form that is completed by all RN during the 5-yearly process of professional license renewal, as legally required based on Continued Nursing Education credits. This form is mandatory and was uploaded to the TNC web-based registration system. The professional licensing renewal requirement enables the sustainability of the cohort, maximizes the follow-up rate, and ensures that information such as health status, job transition, and intention to leave the nursing career are regularly monitored. Second, mortality data generated by the National Civil Registration are linked with the TNC database; confidentiality on personal data is strictly observed throughout.

This report presented details of study design and administration of the TNCS. We also provided details of weighting for statistical methods to be used with the TNCS data. We strongly recommended that any analyses should implement weights we provided in the report, or at least, should explore how weighting affects their conclusions. In this report, we found that Thai nurse were aging. About half of them, $48.5 \%$, were older than 44 years. The average age was 43.7 years old. However, this is partly due to that older nurses participated in the TNCS more than the younger. We then sought to 
get the average age based on the TNC database- it was 37 years. This was slightly younger when compared to what was reported in a study in the United States which estimated that by 2008 the average age of RNs was 45.4 years, with more than $40 \%$ of the $\mathrm{RN}$ workforce were older than 50 years [10].

We found that $15.4 \%$ of Thai RNs intended to leave nursing career someday during their employments. However, the percentage of intention to leave within the next 2 years was $4.3 \%$. By this proportion, based on the current RN population in Thailand, it is approximately 20,000 RNs who intended to leave their careers in the next two years. This could be an alarmingly high turnover rate.

\section{Conclusions}

Health status of the current RNs were generally satisfactory. However, Thailand shares the same nursing crisis as many other countries, with a high proportion of aging nursing workforce, high rate of intention to leave nursing career, and low number of new entry nurses. Further studies are needed to investigate root causes of the crisis so that specific measures can be formulated to minimize the problem.

\section{Availability of data and materials}

All original data were archived in a secure database server (http://www.thainursecohort.org). This server archived all study material and served as the portal for cohort members to respond to the survey questionnaire, view the survey summary results in a real-time manner, and participate in an electronic forum for information exchange among cohort members. Cohort members and other Thai researchers are encouraged to use the data for research purposes at no cost. To access data, researchers are required to submit an analysis plan proposal (APP) (via http://tncs.damus.in.th). The Data Archival for Maximize Utilization (DAMUS) Committee is responsible for reviewing and approving research requests. Researchers with an approved APP are required to provide regular progress updates until publication of their work. Currently, all study materials are in the Thai language; international researchers will need to contact the DAMUS Committee to collaborate with the TNCS and access the data.

\footnotetext{
Abbreviations

AEC: ASEAN Economic Community; APP: analysis Plan Proposal; ASEAN: association of Southeast Asian Nations; DAMUS: data Archival for Maximize Utilization Committee; EQ-5D: EuroQol five-dimension questionnaire; IPAQ: international Physical Activity Questionnaire; JCQ: job Content Questionnaire short version; RN: registered nurse; SEA: South East Asia; TNC: Thailand Nursing and Midwifery Council; TNCS: Thai Nurse Cohort Study.

\section{Competing interests}

The authors declare that they have no competing interests. This material is based on the TNCS, which was financially supported by the Human Resource for Health Research and Development Office, the Health System Research Institute, the International Health Planning and Policy, and the Thailand Nursing and Midwifery Council.
}

\section{Authors' contributions}

$\mathrm{KS}, \mathrm{VT}, \mathrm{PT}$, and BT initiated the concept and wrote the original manuscript. $\mathrm{TT}$, WT, PP, NC, KT, and CT provided constructive criticism and edits of the drafts of the manuscript. BT wrote the analysis plan and the first draft of the manuscript with the support of KS and VT. KT and NC conducted the data analysis. All authors have read and approved the final version of the manuscript.

\section{Author information}

$\mathrm{KS}, \mathrm{VT}, \mathrm{TT}$, and BT are affiliated with the Thai Nurse Cohort Study (TNCS), International Health Policy Program, Ministry of Public Health, Tiwanon Rd. Nonthaburi 11000, Thailand. PT and CT are affiliated with the Faculty of Nursing, Chiang Mai University, Chiang Mai, 50200, Thailand. WT, PP, NC, KT, and BT are affiliated with the Data Management and Statistical Analysis Center (DAMASAC), Faculty of Public Health, Khon Kaen University, 40002, Thailand. BT is affiliated with the Department of Biostatistics and Demography, Faculty of Public Health, Khon Kaen University, Khon Kaen, 40002, Thailand.

KS is currently the Vice President of the Thailand Nursing and Midwifery Council. VT is currently the Director of the International Health Policy Program of Thailand. BT is currently the Director of the Data Management and Statistical Analysis Center at Khon Kaen University, Thailand.

\section{Acknowledgments}

The authors gratefully acknowledge the late Professor Tada Yipintsoi, who initiated and encouraged the investigators to form the cohort, for his advice and critical contributions. We thank the Human Resource for Health Research and Development Office, the Health System Research Institute, the International Health Policy Program, the Thailand Nursing and Midwifery Council, and the Medical Research Network of Thailand for their support and advice. The authors also thank Professor Wichit Srisuphan, the former President of the Thailand Nursing and Midwifery Council, for her advice and provision of the nurse registration database to develop a sampling frame. We thank all staff of the data management center for their assistance in data management, and all cohort members for their valuable and continued participation.

\section{Funding}

The TNCS was locally initiated and domestically funded by the Human Resource for Health Research and Development Office, the Health System Research Institute, and the International Health Policy Program of Thailand. The cost of paper-based surveys is substantial due to postal services, but evolution towards web-based surveys will minimize costs and ensure financial sustainability.

\section{Author details}

${ }^{1}$ Thai Nurse Cohort Study (TNCS), International Health Policy Program, Ministry of Public Health, Tiwanon Rd., Nonthaburi 11000, Thailand. ${ }^{2}$ Faculty of Nursing, Chiang Mai University, Chiang Mai 50200, Thailand. ${ }^{3}$ Data Management and Statistical Analysis Center (DAMASAC), Faculty of Public Health, Khon Kaen University, Khon Kaen 40002, Thailand. ${ }^{4}$ Department of Biostatistics and Demography, Faculty of Public Health, Khon Kaen University, Khon Kaen 40002, Thailand.

Received: 23 September 2015 Accepted: 3 February 2016

Published online: 17 February 2016

\section{References}

1. Buchan J, Calman L. The global shortage of registered nurses: an overview of issues and actions. 2005. http://www.icn.ch/images/stories/documents/ publications/GNRI/Global_Shortage_of_Registered_Nurses_Executive_ summary.pdf. Accessed 07 Feb 2016.

2. Chan ZC, Tam WS, Lung MK, Wong WY, Chau CW. A systematic literature review of nurse shortage and the intention to leave. J Nurs Manag. 2013; 21(4):605-13.

3. World Health Organization. Global Health Observatory Data Repository: Density of nursing and midwifery personnel (total number per 1000 population, latest available year). 2015. http://www.who.int/gho/health_ workforce/nursing_midwifery_density/en/. Accessed 21 Sep 2015.

4. International Council of Nurses and Florence Nightingale International Foundation. The Global Nursing Shortage: Priority Areas for Intervention. 2006. http://www.icn.ch/images/stories/documents/publications/GNRI/The_ Global_Nursing_Shortage-Priority_Areas_for_Intervention.pdf. Accessed 07 Feb 2016. 
5. Janiszewski GH. The nursing shortage in the United States of America: an integrative review of the literature. J Adv Nurs. 2003;43(4):335-43.

6. Duvall JJ, Andrews DR. Using a structured review of the literature to identify key factors associated with the current nursing shortage. J Prof Nurs. 2010; 26(5):309-17.

7. The Association of Southeast Asian Nations (ASEAN). Asean economic community blueprint. 2008. http://www.asean.org/wp-content/uploads/ archive/5187-10.pdf. Accessed 21 Sep 2015.

8. Kingma M. Nurses on the move: a global overview. Health Serv Res. 2007; 42(3 Pt 2):1281-98.

9. Nevidjon B, Erickson JI. The nursing shortage: solutions for the short and long term. Online J Issues Nurs. 2001;6(1):4.

10. Buerhaus Pl, Staiger DO, Auerbach DI. Implications of an aging registered nurse workforce. JAMA. 2000;283(22):2948-54.

11. World Health Organization. The world health report 2006: working together for health. 2006. http://www.who.int/whr/2006/en/. Accessed 07 Feb 2016.

12. Winters-Moorhead C, Kooker BM. Four indicators for monitoring progress in addressing the registered nurse workforce shortage in Hawai'i. Hawaii Med J. 2008;67(12):322-5.

13. Palmer $\mathrm{C}$. The nursing shortage: an update for occupational health nurses. AAOHN J. 2003:51(12):510-3.

14. Colditz GA, Manson JE, Hankinson SE. The Nurses' Health Study: 20-year contribution to the understanding of health among women. J Womens Health. 1997:6(1):49-62.

15. Colditz GA, Coakley E. Weight, weight gain, activity, and major illnesses: the Nurses' Health Study. Int J Sports Med. 1997;18 Suppl 3:S162-170.

16. Hundrup YA, Simonsen MK, Jorgensen T, Obel EB. Cohort profile: the Danish nurse cohort. Int J Epidemiol. 2012:41(5):1241-7.

17. Hayashi K, Mizunuma H, Fujita T, Suzuki S, Imazeki S, Katanoda K, et al. Design of the Japan Nurses' Health Study: a prospective occupational cohort study of women's health in Japan. Ind Health. 2007;45(5):679-86.

18. Fujita T, Hayashi K, Katanoda K, Matsumura Y, Lee JS, Takagi H, et al. Prevalence of diseases and statistical power of the Japan Nurses' Health Study. Ind Health. 2007;45(5):687-94.

19. Turner C, Bain C, Schluter PJ, Yorkston E, Bogossian F, McClure R, Huntington A. Cohort Profile: The Nurses and Midwives e-Cohort Study-a novel electronic longitudinal study. Int J Epidemiol. 2009;38(1):53-60.

20. Camerino D, Mansano Sarquis LM. Nurses' working conditions, health and well being in Europe (Nurses' Early Exit Study). Prof Inferm. 2010;63(1):53-61.

21. Hasselhorn HM, Tackenberg P, Kuemmerling A, Wittenberg J, Simon M, Conway PM, et al. Nurses' health, age and the wish to leave the professionfindings from the European NEXT-Study. Med Lav. 2006;97(2):207-14.

22. Hundrup YA, Simonsen MK, Jorgensen T, Obel EB. Cohort profile: the Danish nurse cohort. Int J Epidemiol. 2012;41(5):1241-7.

23. Landsbergis PA, Schnall PL, Pickering TG, Schwartz JE. Validity and reliability of a work history questionnaire derived from the Job Content Questionnaire. J Occup Environ Med. 2002;44(11):1037-47.

24. Cheung K, Oemar M, Oppe M, Rabin R. EQ-5D User quide: Basic information on how to use EQ-5D. 2009. http://www.eurogol.org/fileadmin/user_upload/ Documenten/PDF/User_Guide_v2 March_2009.pdf. Accessed 14 Jan 2016.

25. Fogelholm M, Malmberg J, Suni J, Santtila M, Kyrolainen H, Mantysaari M, et al. International Physical Activity Questionnaire: Validity against fitness. Med Sci Sports Exerc. 2006;38(4):753-60.

26. Ogata Y, Nagano M, Fukuda T, Hashimoto M. [Job retention and nursing practice environment of hospital nurses in Japan applying the Japanese version of the Practice Environment Scale of the Nursing Work Index (PES-NWI)]. [Nihon koshu eisei zasshi] Japanese J Public Health. 2011;58(6):409-19.

27. Miyazaki Y, Raudenbush SW. Tests for linkage of multiple cohorts in an accelerated longitudinal design. Psychol Methods. 2000;5(1):44-63.

\section{Submit your next manuscript to BioMed Central and we will help you at every step:}

- We accept pre-submission inquiries

- Our selector tool helps you to find the most relevant journal

- We provide round the clock customer support

- Convenient online submission

- Thorough peer review

- Inclusion in PubMed and all major indexing services

- Maximum visibility for your research

Submit your manuscript at www.biomedcentral.com/submit
() Biomed Central 